Годищњак Филозофског̄ факулиеиейа у Новом Саду, Къиг̄a ХХХVIII (2013)

Annual Review of the Faculty of Philosophy, Novi Sad, Volume XXXVIII (2013)

Dubravka Valić Nedeljković

Filozofski fakultet Univerziteta u Novom Sadu

UDK 316.774:[81'42:004.738.5

Originalni naučni rad

\title{
VIRTUELNA JAVNOST O „PREDLOGU DEKLARACIJE O ZAŠTITI USTAVNIH I ZAKONSKIH PRAVA AUTONOMNE POKRAJINE VOJVODINE“**
}

U radu se analiziraju diskursne strategije korisnika najposećenijih multimedijalnih portala na srpskom jeziku, koji imaju i svoja zemaljska izdanja. Povod za postavljanje komentara su novinarski tekstovi o „Predlogu deklaracije o zaštiti ustavnih i zakonskih prava autonomne pokrajine Vojvodine", dokumentu koji nije bio, pre najave njegovog usvajanja, na širokoj javnoj raspravi. Internet je bio jedini, iako virtuelni, javni prostor, koji je građanima omogućio da iskažu svoje mišljenje o dokumentu. Osnovna istraživačka metoda je analiza medijskog diskursa. Jedinica analize je komentar korisnika sa svim pripadajućim elementima. Korpus čini ukupno 541 komentar postavljen na ukupno osam multimedijalnih portala. Analizom je uočeno da su netizensi, iako su ostavljali komentare na novinarske tekstove, zanemarili taj povod, iskoristili su tu šansu da bi otvorili javnu debatu u virtuelnom prostor-vremenu o kontroverznom političkom dokumentu. Identifikovano je ukupno četrnaest diskursnih strategija u sva četiri posmatrana perioda u aprilu 2013. Kontekst događaja o kojem su mediji izveštavali direktno je uticao na sadržaj i strategije koje su netizensi odabirali za postavljanje svojih komentara.

Ključne reči: multimedijalni, portal, deklaracija, autonomija, komentar, netizens

\section{UVODNA RAZMATRANJA}

Novi mediji su nosioci „Digitalne revolucije“ kao „dela globalne kulturne transformacije koja ima isti efekat na svet koji je svojevremeno imala štampa, ili elektrifikacija" (Creeber \& Martin, 2009 : 5). Internet je promenio pre svega političku sferu, ali i način na koji se koriste informacije o događajima, pojavama i ljudima o čemu nas izveštavaju i onlajn mediji. Ovaj fenomen nije do sada dovoljno istražen. Benjamin i Jerit (2012:190) upozoravaju da dosadašnja istraživanja nisu dala jasan odgovor na to da li je Internet postao zamena, ili je samo komplementarni izvor tradicionalnim medijima. Istraživanje ovih autora ukazalo je na to da je Internet zamenio pre svega novine i radio, ali ne svuda podjednako. Zaključuju (Benjamin i Jerit 2012 : 206) da je zamena tradicionalnih sa novim medijima uslovljena, pre svega, sadržajem i potrebom svakog pojedinačnog korisnika. Podstaknuta je i time što omogućava direktnu interaktivnost korisnika Interneta sa postavljenim sadržajem na mreži, akterima društvene prakse i samim medijem.

* dnvalic@gmail.com 
Podsetimo da su mediji masovnog komuniciranja oduvek težili interaktivnosti sa auditorijumom. Takođe i auditorijum je pokazivao interes da iskaže svoj stav o medijskom sadržaju ili pojavi, događaju, odnosno akterima društvene prakse. Tako tradicionalna štampa otvara stranicu za pisma čitalaca ${ }^{2}$, analogni radio uključuje slušaoce u program „uživo", a televizija to ostvaruje tako što publiku dovodi u studio gde se snimaju ,javne emisije” i omogućuje prisutnima da postavljaju pitanja učesnicima i daju mišljenje o temi.

Sa Internetom interaktivnost dobija sasvim novu dimenziju. Interaktivnost predstavlja mogućnost koju Internet pruža korisnicima da direktno, bez intervencije uredništva, utiču na sadržaj, odnosno formu, novih digitalnih medija. Istovremeno korisnici stupaju i u međusobni virtuelni dijalog čiji rezultat može biti formiranje javnog mnjenja o određenoj temi. Ukoliko intervencija administratora medijskog portala i postoji, ona je post festum. Tačnije, neodgovarajući sadržaji opterećeni govorom mržnje se uklanjaju tek na intervenciju drugih korisnika. To Internet čini najdemokratičnijim prostor-vremenom i smatra se da je to njegova osnovna karakteristika $\mathrm{i}$ vrednost. Istovremeno to je i opasnost koja preti Internetu da bude neuređeni prostor-vreme koji omogućava neograničenu diskriminaciju drugog i drugačijeg.

Kiousis (prema Miller, 2011 : 16) prepoznaje tri načina interaktivnosti. Prvi se već implicitno nalazi u samoj tehničko-tehnološkoj strukturi kompjuterski posredovane komunikacije; drugi je sociološki koji vodi računa o društvenom kontekstu u kojem se poruke razmenjuju; a treći psiho-socijalno orijentisani aspekt interaktivnosti ogleda se u direktnoj vezi sa percepcijom korisnika i odnosi se na preuzimanje ,pasivne” ili ,aktivne” uloge u participaciji digitalnih medijskih sadržaja.

Novi mediji, za razliku od tradicionalnih, su proizvedeni u postindustrijskom informatičkom kapitalizmu, smatra Miller (2011: 25) okrenutom ,individualnim izborima, nasuprot masovnoj potrošnji” tradicionalnih medija. Stalno su u promeni (updates), ponovnom kreiranju i ,postoje u potencijalno infinitnim verzijama”. To ih čini vanvremenskim i vanprostornim u neprestanom procesu menjanja. Zbog ove osobenosti internetskih multimedijalnih platformi, koje omogućavaju korisnicima da učestvuju u kreiranju sadržaja i nakon dugog vremena od postavljanja primarne poruke, veoma je teško utvrditi jedinicu analize. Podsetimo da iako analiza diskursa omogućuje da se jedinica analize prilagodi cilju i predmetu istraživanja, teškoća proizilazi iz činjenice da novinarski tekst i pripadajući mu komentari nisu dati jednom za uvek, već su njihov broj, forma i sadržaj u neprestanom procesu menjanja. U menjanju sadržaja mogu da učestvuju kako novinari tako i korisnici.

Jedan od osnovnih argumenata da se ne ograniči interaktivnosti na Internetu jeste da:

„prava demokratizacija komuniciranja ne bi trebalo samo da omogući građanima da budu 'slobodni konzumenti (medija)' već, pre svega, da aktivno kreiraju

Podsetimo da je u Politici početkom devedesetih upravo ta „rubrika” iz ideoloških i ubeđivačkih, ratno huškačkih, razloga sa pretposlednje stranice prebačena na drugu, kako bi se kroz pisma čitalaca dao legitimitet nacionalističkoj politici tadašnjeg režima u Srbiji. 
i menjaju poruke od interpersonalne do masovne komunikacije, sa ciljem da ostvare njihove interese i potrebe u saradnji sa drugima" (Splihal, 2009 : 392).

Kate Nash (2012 : 199) objašnjavajući potrebe korisnika za interaktivnošću i „proizvodnjom” poruka koje postavljaju na Interenet, navodi Ričardsona kao izvor, koji ističe da je:

„korisnička produkcija moguća samo ukoliko je korisnik stavljen u proaktivnu poziciju". Ričardson (prema Nash, 2012 : 199) identifikuje tri forme interaktivnosti: interaktivnost korisnika u kojoj je sadržaj fiksiran, a korisnik interpretira, evaluira, i aktivan je u alternativnom domenu. Druga je, procesorska interaktivnost u kojoj korisnik ima neku mogućnost da doprinese, mada su sadržaj i forma doprinosa fiksni, na primer slanje imejla. Na kraju, treća je generatorska interaktivnost $\mathrm{u}$ kojoj korisnik zauzima prostor u kojem je autor sadržaja, na primer otpočinjanje nove diskusije na forumu".

Tip interaktivnosti, odnosno ,profil” korisnika, nije jednom zauvek dat i jednoznačan. On zavisi od toga šta se traži na „Netu”, odnosno šta je motiv korisnika za interakciju i kako se njegov/njen doprinos uklapa u već postavljene sadržaje, kao na primer tekst novinara, ili komentari drugih korisnika, u onlajn medijima.

Grupa autora (Meyen, M., et. al, $2010: 877-879$ ) u veoma inspirativnom istraživanju, identifikovala je kroz dubinske intervjue sedam profila korisnika Interneta. Virtuozi su neprekidno onlajn. Internet je prostor-vreme u kojem je po njihovom mišljenju akumuliran „kulturni i društveni kapital”. Oni na Internetu traže i pružaju informacije. Pripadnici ove grupe su mladi, obrazovani, iz srednjeg i višeg staleža, okrenuti karijeri. Drugu grupu čine Profesionalci. Internet koriste za posao, pre svega kao izvor informacija i prostor za istraživanje novih poslovnih mogućnosti. Pripadnici su više srednje klase. Imaju između 30 i 40 godina, veoma su obrazovani i pretežno muškarci. Ovisnicima je Internet mesto gde moraju da budu, oni su na mreži od buđenja do odlaska na počinak. Socijalne mreže su njihov prvi izbor i tu su veoma aktivni. Na Internetskim društvenim mrežama traže ,jake" i ,labave” veze sa drugim korisnicima. Pretežno su mladi, ne baš zadovoljni svojom svakodnevicom. Efikasni su na Internetu samo dva do tri sata ujutro. Koriste ga kao „besplatni buvljak”. Dominantan motiv je sticanje kulturnog kapitala. Uglavnom su u ovoj grupi penzioneri. Često ga koriste za zadovoljavanje posvećenosti nekom hobiju. Druželjubivi su korisnici samo socijalnih mreža poput Fejzbuka, Partifens i sličnih. Uglavnom su to mlade devojke, još u procesu obrazovanja. Oprezni na Internetu su samo nekoliko puta sedmično, uglavnom na Guglu, Vikipediji i pomalo na šoping sajtovima. Internet im koristi da reše dnevne probleme. Ako izostanu sa Veba to ni malo neće poremetiti njihovu dnevnu rutinu. Pripadnici su onlajn samo da bi bili u kontaktu sa rođacima i prijateljima uprkos tome što sumnjaju u nove tehnologije koje ih plaše. Više vole da telefoniraju i pišu pisma. U ovu grupu se svrstavaju uglavnom žene i to majke, domaćice, penzionerke. Njihove godine nisu toliko bitne, koliko njihov status i motiv.

Osim navedenih Tang i Sampson (2012 : 459) definišu još jednu grupu, posebno značajnu za naše istraživanje, i nazivaju je ,netizens”. Termin označava proaktivne 
korisnike Interneta. Njima Internet služi kako za promociju sopstvenih stavova tako i za komentarisanje sadržaja koje objavljuju uticajni mediji. Oni su posebno aktivni kada su u pitanju dnevno-političke teme.

Tang i Sampson (2012 : 457) naglašavaju da ,putem izražavanja javnog mnjenja na Internetu obični ljudi mogu da kolektivno oblikuju i čak direktno utiču na uobičajenu agendu u vestima". Prema ovim autorima (2012:459) Internet omogućuje ljudima alternativni kanal putem kojeg mogu na relativno bezbedan način da izraze svoje mišljenje i da komentarišu sadržaje koje objavljuju informativno-politički medije koji imaju najveći uticaj na javnost.

Castells (2007) smatra da Internet može da služi kao jedno alternativno sredstvo za formiranje javnog mnjenja što je tradicionalno domen masovih medija koji su, opet, tradicionalno pod uticajem vladajućih elita.

Michelson dodaje da (2007) u interaktivnom procesu na Internetu, snažno virtuelno javno mnjenje može da ponudi način na koji u državno kontrolisanim medijima obrađena tema može biti legitimnije postavljena. Taj proces produžava i produbljuje javni interes o pitanjima koja bi inače mogla biti skrivena od javnosti.

Znači, da sumiramo, različiti tipovi korisnika Interneta na različite načine i sa različitim ciljem stupaju u interaktivnost. Ono što nas zanima, $u$ istraživanju prezentovanom u ovom radu, su korisnici netizensi koji teže da se aktivno uključe u javnu debatu o pitanju od izuzetnog značaja za celu zajednicu, a za to im je virtuelno vreme-prostor bila jedina mogućnost. U ovom slučaju je to „Predlog deklaracije o zaštiti ustavnih i zakonskih prava Autonomne Pokrajine Vojvodine”, dokument koji nije bio na širokoj javnoj raspravi pre objavljivanja na sajtu Vlade i pre stavljanja na uvid poslanicima skupštine Vojvodine. Inače, podsetimo, to se podrazumeva za predlog teksta dokumenta koji se tiče političkog statusa jednog dela zemlje.

\section{CILJ}

Cilj istraživanja je da se utvrde diskursne strategije „netizensa” koji su na najposećenijim medijskim portalima ostavljali komentare na novinarske tekstove o „Predlogu deklaracije o zaštiti ustavnih i zakonskih prava Autonomne Pokrajine Vojvodine".

Imajući u vidu podeljenost vlasti u Pokrajini, zatim već dugogodišnji negativni stav dela javnosti Srbije van Vojvodine o „dozvoljenom” stepenu autonomije, kontroverznim odrednicama Ustava Srbije (2006) i Statuta Pokrajine (2009) i Zakona o nadležnostima APV koje su u velikoj meri osporene od Ustavnog suda Srbije, čime se u velikoj meri ograničava autonomija pokrajine Vojvodine, od posebnog je interesa analizirati komentare internetskih korisnika na novinarske tekstove u onlajn izdanjima vodećih medija u Srbiji o navedenom dokumentu čiji je cilj poštovanje Ustava Srbije (2006). U „Predlogu deklaracije” konstatuje se povreda prava i nadležnosti pokrajinskih organa, a od republičkih vlasti se traži poštovanje prava i obaveza prema Vojvodini. 


\section{METOD, JEDINICA ANALIZE I KORPUS}

Osnovna metoda je analiza medijskog diskursa. Jedinica analize je komentar korisnika sa svim pripadajućim elementima (datum, vreme postavljanja, potpis, tekst, emotikoni, ikone, preporuke). Primeri u tekstu ovoga rada citirani su u originalnom obliku onako kako su postavljeni na portal bez intervencija u sadržaju, pravopisu, gramatici, jeziku i pismu.

Korpus čine komentari korisnika najposećenijih multimedijalnih portala u Srbiji objavljenih tokom aprila 2013. godine.

Na ključne reči „Deklaracija o zaštiti ustavnih i zakonskih prava Autonomne Pokrajine Vojvodine" pregledom na pretraživaču Gugl 28.04.2013. identifikovano je 151000 pogodaka. Od toga je za analizu izdvojen ukupno 541 komentar postavljen na ukupno osam mutimedijalnih portala u četiri značajna perioda za pitanje političkog opstanka „Predloga deklaracije o zaštiti ustavnih i zakonskih prava Autonomne Pokrajine Vojvodine” tokom aprila 2013.

Subota 6. april 2013. Vlada Vojvodine najavila za sredu, 10. april, usvajanje deklaracije o pravima pokrajine. Komentari su postavljani 6 i 7. aprila.

Četvrtak 11. april 2013. Vlada Vojvodine objavila tekst „Predloga deklaracije o zaštiti ustavnih i zakonskih prava Autonomne Pokrajine Vojvodine“. Najavljene demonstracije protivnika „Deklaracije”. Komentari su postavljani 11.,12. i 13. aprila 2013.

Ponedeljak 15. do četvrtka 23. april 2013. usaglašavanje teksta „Predloga deklaracije", međupartijski pregovori.

Četvrtka 25. april 2013. osnovan pokrajinski Odbor za pitanja ustavno-pravnog položaja Vojvodine. Komentari su postavljani 25. i 26. aprila 2013.

Praćeni su najposećeniji multimedijalni portali domaćih štampanih i elektronskih medija koji se smatraju relevantnim informativno-političkim glasilima među kojima su i nacionalni i pokrajinski javni servis: http://www.rts.rs, http://www.rtv.rs, http://www.b92.rs http://www.blic.rs, http://www.novosti.rs. Zatim je pregledan portal najkontroverznijeg nacionalnog tabloida http://www.kurir-info.rs. Pregledan je i najposećeniji portal lokalnog radija u Vojvodini http://www.021.rs; kao i portal internacionalne radio stanice sa naglašenim informativno-političkim programom na srpskom jeziku http://www.slobodnaevropa.org.

\section{ANALIZA}

Prvi analizirani period (6. i 7. april 2013) obuhvata 85 komentar na tekstove objavljene u Blicu onlajn, Kuriru-info i na sajtu radija Slobodna Evropa. Tada je prvi put najavljen „Predlog deklaracije o zaštiti ustavnih i zakonskih prava Autonomne Pokrajine Vojvodine", koji je odmah izazvao burnu reakciju političara i medija. U virtuelnom prostor-vremenu na multimedijalnim portalima na relativno malobrojne medijske tekstove o ovom događaju netizensi su komentarima iskazali nezadovoljstvo već samom idejom postojanja „nekakve deklaracije” o Vojvodini, kao i time što se dokument pojavio u kontroverznom trenutku za Srbiju. Podseti- 
mo da je to vreme intenzivnih pregovaranja predstavnika vlada Srbije i Kosova. Uspeh ovih pregovora je direktan uslov za dobijanje datuma za otpočinjanje onih drugih pregovora, tačnije za članstvo Srbije u Evropskoj uniji. Podrška tekstu gotovo da je izostala. Najčešće su se komentatori fokusirali na ličnost predsednika Vlade Vojvodine u negativnom smislu. Nije uočen dijalog među komentatorima.

Netizensi su u kreiranju svojih poruka-komentara koristili 10 različitih strategija.

Referiranje na glavnog aktera je diskursna strategija kojom se sam dokument potpuno zanemaruje. U fokusu je osoba/partija koju je virtuelna javnost prepoznala kao uzrok moguće političke nestabilnosti. Karakteristično za ovu strategiju je što se netizensi obraćaju direktno osobi koja je u fokusu.

Primer 1 Novosti

Milica

Jao Pajticu vec mi se povraca od tebe i takvih kao ti u ovoj jadnoj zemlji.

Ili tu osobu ne imenuju, ali podrazumevajuće razumevanje omogućuje da se dekodira akter bez šuma u komuniciranju.

Kurir

živim u Vojvodini ali stvarno ne znam o čemu ovaj ludak priča.mislim da bi ga trebalo optužiti za veleizdaju jer Vojvodina neće da se odvaja ni od kog, a o ovom lopovu se odavno zna sve! organi reda radite svoj posao. Živela Srbija!!!

Osim referiranja na osobu, korisnici se obraćaju i partiji čiji je osoba član. Na implicitnom nivou to znači da komentatorka smatra da je partija ta koja je hijerarhijski nadređena osobi bez obzira što je reč o predsedniku Vlade, tačnije da je društvena moć koncentrisana u partijama.

Primer 2: Kurir

MiroslavNS

Onaj ko misli daje ovo sve slucajnost grdno se vara,sad je mislim i onim najgorim skepticima jasno ko je ko u ovoj zemlji. DS svesno i instruirano doliva ulje na vatru u trenutku kada se donosi odluka o statusu Srba na Kosovu tj. da li ce ostati da zive ali normalno i ljudski ili ce biti proterani, mislite da su dva rialitija krenula bas sad u vreme ka ... više

Strategija Ad hominem izražena je kroz govor mržnje prema pojedincu koji je $\mathrm{u}$ fokusu komentatora.

Primer 3: Novosti

Tale sanjin:

ko je uopste ovaj covek i odakle se stvorio. ukoliko je tacno da je strani drzavljanin, kako je dosao na tako visoku funkciju u svakoj ekonomsko politickoj svinjariji ima poneko ko ima bar jos jedan pasos. niko od njih nije ovde doneo nista, a otisao je sa ogromnim kapitalom.

neša car

Bilo bi zanimljivo grafički istražiti kako će izgledati Bojan Pajtić kada izađe iz zatvora posle dugogodišnje robije zbog afere „Agrobanka”. 
Referiranje na dokument je u ovom periodu bila najređa strategija. Kada se koristi kombinuje se sa strategijom Referiranje na glavnog aktera. Očigledno je da su se korisnici kreirajući komentare rukovodili stilskom figurom pars pro toto i dokument koji je proizvod stručnog tima vlade Vojvodine poistovetili sa predsednikom te Vlade.

Primer 4 Slobodna Evropa

Vojvođanin

Deklaracija je Pajtićev i Vojvođanski Rubikon, posle kojeg više nema nazad. I to mora biti jasno svima. Sve granice trpeljivosti i strpljenja su odavno pređene - a Pretnje koje su usledile nakon svega su takve, da bi samo lud i suicidalan odustao.

Strategija Zamene teze - komentatori umesto o dokumentu ili ličnosti koja je najavila usvajanje dokumenta, govore o drugoj temi, u ovom slučaju, o teškoj materijalnoj situaciji građana.

Primer 5 Novosti

Dule62

Prava nas radnika u Vojvodini su daleko od moderne Evropske prakse. Pogledajte nase kolektivne ugovore. To kako mi danas zivimo u Vojvodini nema veze sa modernom Evropskom praksom.

Strategija poređenja ima četiri varijeteta: Vojvodina jednako Kosovo (Primer 6); svet i mi (Primer 7); susedi i mi (Primer 8); istorija i sadašnjost (Primer 9). Ovo je veoma često korišćen model strukturisanja komentara korisnika.

Primer 6 Novosti

Krle

Pa ovaj narod je lud kad ne shvata da je to korak od otcepljenja. A mi smo i dalje nemi posmatraci. Kao u slucaju Kosova.

U Primeru 6 se poredi Srbija sa Kosovom, a zajednički imenitelj je ,sudbina naroda će biti ista kad se ocepi Vojvodina, Srbi će biti progonjena manjina".

Primer 7 Novosti

\section{Mikaalas}

Ako se nalazite u Australiji, mozete biti ili Australijanac ili stranac. U Americi, Amerikanac ili stranac... kao i svugde u svetu. Jedino kod nas svako moze da bude kako mu se hoce"

Primer 8 Novosti

\section{Branko}

Srbi bi mogli da nauce od Hrvata kako se voli i brani zemlja u Hrvatskoj je apsolutno nemoguce da njihovi politicari zagovaraju separatizam.

Primeri 7 i 8 kao zajednički element koji omogućuje poređenje je „ugledajmo se na one koji imaju bolju praksu". 
Primer 9 Novosti

Radenko

Kosovo nisu odcepili Siptari koji su tu ziveli do 1945. god vec albanci koje je naselio Josip Broz 1945-1946. Isti slucaj ce i sada da se dogodi sa Vojvodinom, njeno odvajanje zagovaraju navodno srbi koji su isto doseljeni posle 1945.

U Primeru 9 porede se događaji iz 1945. i 2013. Zajednički imenitelj je „već viđeno".

Deveta strategija je Ja nudim rešenje. Reč je najčešće o veoma radikalnim i nedemokratičnim rešenjima koja su neprimenljiva u demokratskim društvima. Ova strategija je često kombinovana sa strategijom Ad hominem koja sadrži otvoreni govor mržnje.

Primer 10 Blic online

Vuk:

Под хитно укинути тај наказни парадржавни, аустроугарско-титоистички анахронизам звани "ап војводина" и једном за свагда разбуцати то легло сепаратизма и лоповлука. Паразите, лопурде, сепаратисте и разбијаче државе - иза решетака!

Strategija Korišćenje poslovica u kojima se sadrži savet za bolju praksu - proverena vekovna narodna mudrost je dovoljan argument koji podrazumeva neupitnu primenu. Ova strategija je uočena u mnogim javnim diskursima i dekonstruiše se kao „zaklanjanje iza autoriteta” koji je deo tradicije i kulturnog nasleđa jedne zajednice i nije moguće takve ,autoritete” staviti pod upit.

Primer 11 Novosti

Bačvanin

Govorio je meni moj deda; ,sto mozes uraditi danas ne ostavljaj za sutra”. Ili „prljavo dvoriste cisti se sa metlom korovacom”. Ili „nova mlada rano izjutra cisti ulicu".

Drugi analizirani period obuhvata 11, 12. i 13. april - Vlada Vojvodine objavila je tekst „Predloga deklaracije o zaštiti ustavnih i zakonskih prava Autonomne Pokrajine Vojvodine", stranke koje se protive dokumentu kao i neke studentske organizacije najavljuju miting protiv „Deklaracije”.

Analizirana su 203 komentara na tekstove objavljene na multimedijalnim portalima Blic (163), Radio 021 (25), RTS (13) i RTV (12). Za razliku od prvog perioda u ovome dominira debata/polemika o samom dokumentu, pošto je od 11. aprila dostupan na sajtu Vlade Vojvodine. Suština interaktivnosti ogleda se u polemisanju u javnoj diskusiji o pitanjima od opšteg interesa, što na kraju kao rezultat može da dovede do formiranja preovlađujućeg javnog mnjenja i u virtuelnom prostor-vremenu Interneta.

U ovom periodu, za razliku od prvog analiziranog, preovlađuje podrška netizensa „Deklaraciji” na navedena četiri multimedijalna portala. 
Uočeno je 11 diskursnih strategija komentatora, većina se podudara sa strategijama uočenim u prethodnom periodu.

Referiranje na dokument je strategija koja je u prvom posmatranom periodu bila najređa, u ovom drugom posmatranom periodu je najprisutnija. Na multimedijalnim portalima se otvorila prava polemika o dve teme: prva je da li dokument zagovara separatizam, a druga, da li su potrebni novi izbori u Vojvodini kao svojevrsni referendum o prihvatljivosti „Deklaracije”.

Primer 11 Blic online

Miodrag

Pa šta je ovde sporno? Pozivaju na poštovanje Ustava Republike Srbije. To bre nije separatizam.

Mimi

@Miodrag : Kad smo kod postovanja ustava ,sta bi sa onim neustavnim elementima iz statuta sto je osporio ustavni sud?

Igor

@Miodrag : Zalazu se za postovanje Ustava koji dozvoljava i tolerise vojvodjanski separatizam, a koji su oni sami skrojili..cekaj malo...

sasa

@.Igor : Kanda ti nemas pojma ko je doneo novi ustav!! pa i pored tod DSS ustava ni taj se ne postuje a isto tako si zaboravio da ustav nije prosao u Vojvodini.

Diskursna strategija Zamena teza - ova strategija samo podseća na strategiju Referiranja na dokument. Razlika je u tome što komentatori težište sa „Deklaracije" pomeraju na polemiku o opravdanosti postojanja Pokrajine Vojvodine kao takve i to ne iz političkih/ideoloških, već iz nekih drugih, realnijih razloga kao što su na primer ekonomski. Na ovaj način prava poruka („Deklaracija je sporan dokument") je skrivena iza egzistencijalnih pitanja.

Primer 12 RTS

Ukinuti odmah

Kome treba nekakav „Parlament Vojvodine” kada se Parlament Republike Srbije nalazi na manje od sat automobilom. Kome trebaju sve nepotrebne paralelne institucije u Novom Sadu kada su za jednu malu zemlju kakva je Srbija i institucije u Beogradu preskupe. Verujte mi, ne zabrinjava me ni secesionizam ni nacionalizam ni neke druge prevazidjene rasprave. Ovde se radi o prostoj ekonomiji. Republika Srbija je mala i ekonomski nerazvijena zemlja. Nepotrebne pare za administraciju treba skresati svuda gde se to da izvesti.

$\mathrm{U}$ narednom primeru je prototipično korišćenje strategije Zamena teze. Za razumevanje ovog komentara valja uključiti istorijski kontekst vremena „Druge Jugoslavije” kada su rudari imali ideološki status „radnika nad radnicima”. Podsetimo da je lik rudara bio i na novčanici, a rudar Alija Sirotanović je ušao i u čitanke. Dakle, kada rudari štrajkuju znači da „država” staje jer je to znak da je 
situacija krajnje ozbiljna. Autorka komentara iz Primera 13 upravo navodeći da „štrajkuju rudari” na implicitan način upućuje poruku da je država u izrazitim problemima koje valja rešavati pre nego politička pitanja tipa „Deklaracija o Vojvodini”.

Primer 13 RTS

Lidija

...aman ljudi štrajkuju rudari.

Strategija Poređenje sa istorijom u ovom period je bila fokusirana na dva perioda. Prvi se odnosio na poređenje sa „Titovom Jugoslavijom”, a drugi sa „Jogurt revolucijom" iz devedesetih koja se smatra početkom ukidanja autonomije Vojvodine.

\section{Primer 14 RTS}

Posle kralja, Tito a posle Tita, svi hoce da budu Tito

Polako titovi pioniri, smirite svoje hormone. Svi biste vi hteli da budete Tito, ali ste rasturili i kraljevinu Jugoslaviju u socijalisticku Jugoslaviju. Ono sto vam je ostalo ne moze da se deli, jer narod se probudio i to ne dozvoljava. A narod je sila.

Primer 15 RTV

Vojvodjanin

Jogurt bis! Obrušavaju se na Vojvodinu. Maskarada evropskih opredeljenja je završena.

Sada mogu da budu ono što jesu: nacionalistički populisti.

Tu su i sendvič demonstranti.

Ljudi smo dogovorićemo se. Sve po cenovniku.

Država plaća prevoz u dolasku i odlasku, sve opravdano, patriotski, transparentno i bez korupcije.

Očekujemo Braciku bis, gajbice i narandže bis.

gerila

@Vojvodjanin

Mozda smo sendvic, jogurt i narandze demonstranti sta da radis kad nismo na platnom spisku CIA.

Strategija Poređenje sa Kosovom je u političkom diskursu Srbije postala kliše kada se polemiše o pitanjima autonomije uopšte koji zatim mediji prenose kao citate aktera događaja. Iz medijskih citata političkog govora ovu strategiju su preuzeli komentatori medijskih sadržaja na Internetu.

Primer 16 Blic online

Srbija-Sta-to-bese-biciklo-drzava

evo reprize u sledecih 10 godina Kosovo No. 2... jednostavno srpska politika prosto tera ljude da se odcepe i normalno da zive. Ja sam zaista srecan sto ne zivim u zemlji Srbiji, dovoljno mi je sto vas gledam na televiziji. 
Strategija Ja nudim rešenje u ovom posmatranom periodu dobila je i dodatnu varijantu Poziv na akciju. Pošto je nakon objavljivanja teksta „Predloga Deklaracije” najavljen miting protiv ovog dokumenta komentatori su se i o tome izjašnjavali. Strategija Poziv na akciju uočena je u komentarima posetilaca Fejzbuk stranica političkih partija pred izbore 2012. Pošto je „Predlog Deklaracije” visokopolitizovan događaj, korelacija mobilizatorskog motiva korisnika je jasno uočljiva. U predizbornoj kampanji je bila „svi na izbore”, a u ovom slučaju „svi na miting”.

Primer 17 RTV

Namigusa

Svi na miting da budu podrska Vucic ...

Strategija Korišćenja poslovica kao snažno ubeđivačkog diskursa koji se oslanja na narodnu tradiciju uočena je i u ovom period uz dodatak opšte poznatih stihova i to u obliku polemike.

Primer 18 RTV

Pancevac

Vojvodina nasa dika....

gerila@Pancevac Samo da nastavim,,,,,veza sa Srbijom jaca od celika.

Nova strategija uočena u ovom period je Mi nasuprot njih koja je uvek markirana govorom mržnje bilo na implicitnom ili eksplicitnom nivou. Ova strategija ima i svoju istorijsku osnovu koja seže još u vreme prve kolonizacije, nakon Prvog svetskog rata, kada su se konfrontirali „starosedeoci” sa „kolonistima/dođošima”. Produbljuje se nakon druge kolonizacije, posle Drugog svetskog rata, da bi dobila svoj radikalniji oblik nakon treće kolonizacije, devedesetih godina XX veka, u vreme sukoba na teritoriji SFRJ.

Primer 19 Blic online

lala

@Intern : Vojvodjani ne zele izbore, zele ih bosanci i srbijanci!!!!

Nova strategija u ovom period je i Insistiranje na proceduri. Ova strategija je prenesena kao model iz političke prakse. Kada se ne želi otvaranje javne rasprave o kontroverznim pitanjima u prvi plan se istakne ,procedura”. Podsetimo da su se značajna pitanja često sklanjala/skidala sa dnevnog reda parlamentarnog zasedanja upravo iz ,proceduralnih razloga”.

Primer 20 Blic online

Fica-Abarth

Koliko se ja razumem ova deklaracija bi trebalo da valjda ide prvo u parlament i da se o njoj raspravlja pa tek onda ako se usvoji objavljuje se u sluzbenom glasniku. redosled je predpostavljam takav. necu da polemisem da li je secesionisticka ili nije. 
Treći posmatrani period obuhvata vreme međupartijskog usaglašavanja dokumenta sredinom aprila 2013. Ukupno je u ovom periodu postavljeno 184 komentara $\mathrm{i}$ to na Blic online (162), B92 (51), RTV (22).

U ovom periodu diskursne strategije korisnika multimedijalnih platformi suzile su se na najprisutniju Referiranje na glavnog aktera, zatim u mnogo manjoj meri na Referiranje na dokument, Zamena teza i Ja imam rešenje. I u ovom periodu kontekst teme o kojoj su novinari u tom periodu izveštavali u potpunosti je odredio fokus diskursnih strategija. Netizensi su se usredsredili ponovo na glavnog aktera (predsednika Vlade Vojvodine) i to ponovo, kao i u prvom analiziranom periodu, sa negativnim predznakom.

Primer 20 Blic online, RTV, B92

Blic online

mistral

Ovo je stvarno smešno kao da je napisao domaći zadatak pa dobio jedinicu pa ajd sad piši ponovo

RTV

tata

Pajtiću, i treba da izbaciš tu rečenicu iz DEKLARACIJE, je NIJE ISTINA da su Vojvođani svojom voljom u Srbiji!

B92

Mile i njegovo pile

Pajtić je totalno skrenuo sa politikom. Napisa čovek neku deklaraciju za koji nema većinu već dozvoljava sebi da ga ucenjuju ligaši. Svima je poznato da su ligaši separatistička stranka u Vojvodini koja je jedva prešla cenzus. Izlazak iz ove zavrzlame je bez sumnje raspisivanje pokrajinskih vanrednih izbora.

Referiranje na dokument za razliku od drugog posmatranog perioda je sporadična strategija u ovom periodu. Kada komentatori u fokus polemike u virtuelnom prostor-vremenu stavljaju sam dokument to je ponovo sa negativnim predznakom.

Primer 21 Blic online

022

Само још једном да разграничимо од чега се држављани Србије штите у рођеној земљи?????

Niki

@022 : Ono što se desilo sa Kosovom služi kao lekcija Srbiji. Svakoi pokušaj bolje sprečiti nego lečiti!

Olivera

@022 : E ka Njegoš si... 
dana

@Mare : Naravno da ni jedan Srbin neće podržati ideju o separatizmu. A u vojvodini je $80 \%$ Srba tako da je ova ideja već unapred propala.

Primer 22

Razocarani-Demokrata

Pa dajte da vidimo deklaraciju kad tvrdite da nema ni S od Separatizma.

Janja

@Razocarani-Demokrata : Da te stvarno zanimalo da procitas deklaraciju, otissao bi na sajt Vlade Vojvodine i procitao je. Tamo je vec danima postavljena. Ili bi je ukucao u pretrazivac i pronasao tekst da te stvarno interesuje. koliko vidim, internet znas da koristis..

U ovom periodu je uočena direktna, intenzivna polemika pojedinih korisnika (primeri 21 i 22) koja bi se mogla razumeti, ne više kao samo iznošenje partikularnih vrednosnih sudova, ili stavova o nekoj temi, već želja za uticajem na stvaranje javnog mnjenja. Uočeni su i primeri koji ukazuju na to da su nekada netizensi, mogućnost multimedijalnog portala da reaguju na novinarski tekst, iskoristili da uzurpiraju virtuelno prostor-vreme „Neta” i pretvore ga u privatnu polemiku i tako zadovolje svoje lične, partikularne, komunikativne potrebe koristeći i strategiju Ad hominem.

Primer 23 RTV

gerila 16. 04. 2013. 10:25

@Tata Ako nisi svojom voljom u Srbiji ti lepo Mamu za ruku pa idi.

Tata 16. 04. 2013. 16:34

@ Tata gerila-tekila, da ti kažem da proučiš malo istorijske činjenice, ne vredi, za to treba bar malo pameti, a tu si kratak, pa ću te ipak poslušati i prošetati.

I u ovom periodu diskursna strategija Ja imam rešenje je korišćena češće za radikalne predloge, a ređe za kreativna rešenja problema.

Primer 24 B92

Hajde, neka budu izbori u Vojvodini! Neka odmetnuti vojvodjanski DS i LSV pokazu svoju ,snagu”. Kladim se da nemaju ni 10\% podrske zajedno! Dosta je bilo!

Rodjena Vojvodjanka

U okviru ove strategije je i Poziv na akciju, kratke jasne poruke koje bi trebalo da mobilišu internetsku javnost da preduzme konkretne aktivnosti van virtuelnog prostor-vremena kojima bi se moglo doći do određenih rezultata.

Primer 25 Blic online

jaiznovogsada

vojvodino, ne popuštaj! 
I na kraju u ovom trećem analiziranom periodu uočen je jedan jedini primer $\mathrm{u}$ celom korpusu u kojem se komentator obraća administratoru najposećenijeg $\mathrm{u}$ Srbiji multimedijalnog portala Blic online - Referiranje na administratora multimedijalnog portala. Dakle, netizens je prepoznao da se ipak i portali kontrolišu i da ih „uređuju” „čuvari kapija”. U komentaru im to zamera jer je „Net” prepoznat kao jedina slobodna zona građanima za iskazivanje stavova i vrednosnih sudova i to na način na koji oni smatraju da je dopustiv.

Primer 26 Blic online

ja_u_rusiji

ajde vi iz Blica da zabranite neregistrovane komentare i glasanje? njihove manipulacije brisanjem kesha, kukisa $i$ ip adres skrivachem prave laznu sliku mishljenja ljudi a u prvi plan guraju hvalospeve $\mathrm{O}$ velikog gospodina, pljuvanje neistomishljenika, i razne pretnje za koje bi u normalnim drzavama guljali tjorku

Poslednji, četvrti, istraživački period (kraj aprila 2013) obuhvata izveštavanje o formiranju pokrajinskog Odbora za pitanja ustavno-pravnog položaja Vojvodine, događaja koji nije izazvao veći interes medija. Pažnju tim izveštajima, ali ne i događaju, posvetila je publika javnog servisa Vojvodine i Blica online, koja je iskoristila mogućnost da postavi ukupno 69 komentara. Ni jedan komentar se nije odnosio na novoformirani Odbor, već je nastavljena polemika o pitanjima o kojima su netizensi postavljali komentare na multimedijalnim portalima tokom celog aprila.

U ovom periodu je tema „Predlog deklaracije o zaštiti ustavnih i zakonskih prava autonomne pokrajine Vojvodine" već polako izlazila iz fokusa netizensa. Pet diskursnih strategija u ovom periodu je bilo podjednako zastupljeno. Izdvajamo primer za strategiju Referisanje na aktera jer se u komentaru netizensa prvi put $\mathrm{u}$ ovom korpusu otvoreno pominje jedna od najprepoznatljivijih karakteristika Vojvodine - multikulturalizam/nacionalne manjine, a komentator je istovremeno pripadnik jedne od nacionalnih zajednica.

Primer 27 Blic online

Jozef-NS

Vojvodina je multinacionalna sredina i tako treba i da ostane. Vlada AP Vojvodine svojom deklaracijom dovodi do negativnih reakcija među svim nacionalnim manjinama koje ne podržavaju navedenu deklaraciju. Najpoželjnije bi bilo da uopšte o tome ne raspravljaju.

Komentatori se, barem u porukama obuhvaćenim ovim korpusom, nisu izjašnjavali kao pripadnici većine, ili manjine, niti se to moglo dekonstruisati na osnovu potpisa pod komentare. Istovremeno briga o održanju multinacionalnosti Vojvodine je bitan element dokumenta o kojem se raspravljalo na „Netu”. Debata o pravima manjina i ljudskim pravima uopšte, izostala je u komentarima netizensa.

$\mathrm{U}$ ovom poslednjem periodu se ponovo pojavljuju dve diskursne strategije koje za osnovu imaju poređenje, a u fokusu je ex-yu i Kosovo. 


\section{Primer 28 Blic online}

dane

kada mozete da priznate kosovo mocete te i vojvodinu da priznate! za slobodnu vojvodinu!

antimitingas

@Bromazepam : Tako ste počeli i sa Kosovom, sa Slovenijom itd. Zar nikad nećete doći pameti?

\section{ZAKLJUČAK}

Analizom je uočeno da su proaktivni komentatori sadržaja na Internetu - netizensi, iskoristili šansu koju im pružaju multimedijalni portali da komentarišu novinarske tekstove, da otvore javnu debatu $\mathrm{u}$ virtuelnom prostor-vremenu o „Predlogu deklaracije o zaštiti ustavnih i zakonskih prava Autonomne Pokrajine Vojvodine", koja je inače izostala među građanima u društveno-politčkoj sferi. Nije ih zanimala novinarska konstrukcija događaja. Ni jedan postavljeni komentar nije referirao na način medijskog izveštavanja o kontroverznom dokumentu. Interesovao ih je sadržaj „Predloga deklaracije”, politički akteri koji su ga kreirali i oni koji su ga osudili, zatim politički trenutak u kojem je tekst plasiran u javnosti, pitanje autonomije i separatizma, ekonomska propast i njeni uzroci. Internet je u ovom slučaju poslužio kao jedno alternativno sredstvo za formiranje, doduše virtuelnog, javnog mnjenja.

Domen tradicionalnih masovih medija jeste da utiču na to šta će građani odabrati sa političke agende kao pitanja prioriteta za zajednicu i da u određenoj meri utiču na formiranje domininirajućeg mnjenja. Istovremeno tradicionalni mediji su u Srbiji izrazito pod uticajem vladajućih političkih i ekonomskih elita koje produkuju događaje i donose odluke koje plasiraju i na Vebu. Internet je još prostor-vreme u kojem se sučeljavaju različita mišljenja bez a priornih ograničenja, osim kada je u pitanju, na primer, pedofilija.

Da li je Internet pravi prostor za javnu debatu i polemiku, ili tek jedan od mogućih, jeste izazov za buduća istraživanja u ovom polju.

U ovom radu nismo mogli u potpunosti da odgovorimo na to pitanje. Bavili smo se samo jednim ograničenim segmentom aktivnosti korisnika na „Netu” i za to utvrdili limitirani korpus.

Cilj je bio da se identifikuju diskursne strategije koje aktivni korisnici multimedijalnih portala koriste u onlajn debati/polemici o veoma važnom političkom dokumentu.

Analizom diskursa komentara utvrdili smo da su diskursne strategije koje su koristili za izražavanje svojih vrednosnih sudova zavisile od samog događaja o kojem su mediji izveštavali u posmatrana četiri perioda tokom aprila 2013. kao i od uređivačke politike portala koji su odabrali da na njega postave svoj komentar. Komentari postavljeni na portalu javnog servisa Vojvodine, Radija 021 i Radija 
Slobodna Evropa snažno su opravdavali „Predlog Deklaracije”; na portalima RTS, B92 bilo je više komentatora za dokument, nego protiv; na Blicu online komentatori su različito reagovali u različitim periodima, ali češće su bili protiv dokumenta; snažno su se suprotstavili i samoj ideji bilo kakve „Deklaracije o autonomiji" korisnici Kurira i Novosti.

Osnovni model u kreiranju diskursnih strategija je bio odabir fokusa, tačnije element kojem su davali prioritet u komentaru (dokument, akteri, dnevno-politička orijentacija, okruženje, ili nešto drugo, potpuno marginalno u odnosu na prototipični model).

Identifikovano je ukupno četrnaest diskursnih strategija u sva četiri posmatrana perioda. Strategije Referiranje na glavnog aktera, Referiranje na dokument, Zamene teze, Poređenje sa istorijskim događajima, Ja nudim rešenje komentatori su koristili podjednako frekventno u svim posmatranim periodima. Međutim, određene strategije poput Insistiranje na proceduri, Lična/privatna polemika komentatora, Poziv na akciju, Referiranje na administratora multimedijalnog portala su korišćene samo u pojedinim analiziranim periodima. Jezik mržnje, neprimeren javnom komuniciranju, je samo sporadično identifikovan u komentarima u kojima su korišćene strategije Ad hominem i Mi nasuprot njih.

$\mathrm{Za}$ naredna istraživanja u okviru Republičkog projekta Digitalne medijske tehnologije i društveno-obrazovne promene valjalo bi identifikovati tipove internetskih korisnika u Srbiji i shodno tome definisati njihove ciljeve i preferencije koje ih motivišu za komentarisanje sadržaja na „Netu”. To bi svakako doprinelo da se dođe do odgovora da li je i u kojoj meri Internet pravi prostor za javnu debatu i polemiku, ili tek jedan od mogućih „medija” za kreiranje javnog mnjenja o pitanjima od opšteg interesa.

\section{LITERATURA}

Benjamin G., \& Jerit, J. (2012). Internet News: Is It a Replacement for Traditional Media Outlets? The International Journal of Press/Politics, 17, 190-213.

Castells, M. (2007). Communication, power and counter-power in the network society. International Journal of Communication, 1, 238-266.

Creeber, G., \& Martin, R. (ed.) (2009). Digital cultures: Understanding New Media.

McGraw-Hill and Open University Press.

Meyen, M., Pfaff-Rüdiger, S., Dudenhöffer, K., \& Huss, J. (2010). The internet in everyday life: a typology of internet users. Media Culture Society, 32, 873-882.

Miller, V. (2011). Understanding Digital Culture. Los Angeles, London, New Delhi, Singapore, Washington DC : SAGE.

Michelson, E. (2007). Climbing the dispute pagoda: grievances and appeals to the official justice system in rural China. American Sociological Review, 72, 459-485.

Nash, K. (2012). Modes of interactivity: analysing the webdoc. Media Culture Society, 34, 195-210.

Splichal, S. (2009). New' Media, 'Old' Theories: Does the (National) Public Melt into the Air of Global Governance? European Journal of Communication, 24, 391-405. 
Statut AP Vojvodine (2009). Službeni list AP Vojvodine br. 17/2009

Tang, L., \& Sampson, H. (2012). The interaction between mass media and the internet in non-democratic states: The case of Chin. Media Culture Society, 34, 457-471.

Ustav Republike Srbije (2006). Službeni glasnik RS br. 83/06

Dubravka Valić Nedeljković

\section{VIRTUAL PUBLIC ON THE “DRAFT DECLARATION ON THE PROTECTION OF CONSTITUTIONAL AND LEGAL RIGHTS OF THE AP VOJVODINA"}

\section{RESUME}

The Internet has primarily changed the political sphere, but also the way in which information about events, phenomena and people are used. This phenomenon hasn't been thoroughly investigated especially if the research focus is directed to interactivity as one of the greatest benefits of the Internet compared to traditional media. Interactivity represents a possibility provided by the Internet to directly, without the intervention of editors, influence the content and form of new digital media. At the same time, users enter into virtual dialogues with each other, so the result can be the forming of public opinion on a particular topic.

The type of interaction, or the "profile" of users, is not given and unambiguous. It depends on what they are being asked to do on-line, or what their motive for the interaction is, how their contribution fits the uploaded contents. From the defined types of Internet users specially important for this study is the so-called "netizens" group. The term indicates proactive Internet users. They use the internet to promote their own attitudes and to comment on contents that influential media publish. They are particularly active when it comes to daily political issues. In this case it is about the "Draft Declaration on the Protection of the Constitutional and Legal Rights of the Autonomous Province of Vojvodina" (in further text, Draft Declaration), a document which wasn't publicly debated before its adoption. The Internet was the only public space that allowed citizens to express their opinion on the document.

The aim of this study was to determine discourse strategies of "netizens" who were leaving comments on the most visited media portals in Serbian language to articles about the "Draft Declaration".

The main research method is the analysis of media discourse. The unit of analysis is a user's comment with all its elements. The corps makes a total of 541 comments posted on eight multimedia portals of public services, newspapers, tabloids and radio stations published in the four major periods important for the political survival of the "Draft Declaration" in April 2013.

Analysis results show that the netizens, although they leave comments on journalistic texts, ignore that occasion, and take advantage of the opportunity to open a public debate in the virtual space-time about the "Draft Declaration".

A total of thirteen discourse strategies were identified. Strategies such as Reference to the main actor, Reference to a document, Replace the thesis, Comparison with historical events, I offer a solution have been used by commentators in all observed periods in equal frequencies. However, certain strategies, such as Insisting on procedures, Personal debates of commentators, Call for action, Reference to the administrator of multimedia platforms were used only in certain periods analyzed. Hate speech, inadequate public communication has only been sporadically identified in the comments which used in Ad hominem and We contrast them strategies. The context of the events directly influenced the content and strategies netizens chose in order to post comments. 
Dubravka Valić Nedeljković

\title{
VIRTUELNA JAVNOST O „PREDLOGU DEKLARACIJE O ZAŠTITI USTAVNIH I ZAKONSKIH PRAVA AUTONOMNE POKRAJINE VOJVODINE"
}

\begin{abstract}
REZIME
Internet je promenio, pre svega, političku sferu, ali i način na koji se koriste informacije o događajima, pojavama i ljudima. Ovaj fenomen nije do sada dovoljno istražen, posebno kada se istraživački fokus usmeri na interaktivnost kao jednu od najvećih prednosti Interneta u odnosu na klasične medije. Interaktivnost predstavlja mogućnost koju mreža pruža korisnicima da direktno, bez intervencije uredništva, utiču na sadržaj, odnosno formu, novih digitalnih medija. Istovremeno korisnici stupaju i u međusobni virtuelni dijalog čiji rezultat može biti formiranje javnog mnjenja o određenoj temi.

Tip interaktivnosti, odnosno „profil” korisnika, nije jednom zauvek dat i jednoznačan. On zavisi od toga šta se od njih traži na „Netu”, odnosno šta je motiv korisnika za interakciju i kako se njegov/njen doprinos uklapa u već postavljene sadržaje, kao na primer u tekst novinara, ili komentare drugih korisnika, u onlajn medijima. Od definisanih tipova internetskih korisnika posebno značajnu grupu za ovo istraživanje čine ,netizensi”. Termin označava proaktivne korisnike Interneta. Njima Internet služi kako za promociju sopstvenih stavova, tako i za komentarisanje sadržaja koje objavljuju uticajni mediji. Oni su posebno aktivni kada su u pitanju dnevno-političke teme. U ovom slučaju je to „Predlogu deklaracije o zaštiti ustavnih i zakonskih prava Autonomne Pokrajine Vojvodine”, dokument koji nije bio, pre najave njegovog usvajanja, na širokoj javnoj raspravi. Internet je bio jedini javni prostor koji je građanima omogućio da iskažu svoje mišljenje o dokumentu u okviru multimedijalnih portala.

Cilj istraživanja je bio da se utvrde diskursne strategije „netizensa” koji su na najposećenijim medijskim portalima na srpskom jeziku ostavljali komentare na novinarske tekstove o „Predlogu deklaracije o zaštiti ustavnih i zakonskih prava Autonomne Pokrajine Vojvodine".

Osnovna istraživačka metoda je analiza medijskog diskursa. Jedinica analize je komentar korisnika sa svim pripadajućim elementima. Korpus čini ukupno 541 komentar postavljen na ukupno osam mutimedijalnih portala javnih servisa, dnevnih novina, tabloida, radio stanica, objavljenih u četiri značajna perioda za pitanje političkog opstanka „Predloga deklaracije o zaštiti ustavnih i zakonskih prava Autonomne Pokrajine Vojvodine” tokom aprila 2013.

Analizom je uočeno da su proaktivni komentatori sadržaja na Internetu - netizensi, iskoristili šansu koju im pružaju multimedijalni portali da komentarišu novinarske tekstove, da otvore javnu debatu u virtuelnom prostor-vremenu o „Predlogu deklaracije o zaštiti ustavnih i zakonskih prava Autonomne Pokrajine Vojvodine".

Identifikovano je ukupno četrnaest diskursnih strategija u sva četiri posmatrana perioda. Strategije Referiranje na glavnog aktera, Referiranje na dokument, Zamene teze, Poređenje sa istorijskim događajima, Ja nudim rešenje komentatori su koristili u svim posmatranim periodima podjednako frekventno. Međutim, određene strategije poput Insistiranje na proceduri, Lična/ privatna polemika komentatora, Poziv na akciju, Referiranje na administratora multimedijalnog portala su korišćene samo u pojedinim analiziranim periodima.

Jezik mržnje, neprimeren javnom komuniciranju, je samo sporadično identifikovan u komentarima u kojima su korišćene strategije Ad hominem i Mi nasuprot njih. Kontekst događaja o kojem su mediji izveštavali u posmatrana četiri perioda tokom aprila 2013. direktno je uticao na sadržaj i strategije koje su netizensi odabirali za postavljanje svojih komentara.
\end{abstract}

